\title{
Pineal Gland Morphology in Relation to Age and Season in Three Canidae Species
}

\author{
Svetlana Kalinina ${ }^{1}$ Viktor llyukha ${ }^{1}$ Lyudmila Uzenbaeva ${ }^{1}$ \\ ${ }^{1}$ Institute of Biology, Karelian Research Centre, Russian Academy of \\ Sciences, Petrozavodsk, Russia \\ Address for correspondence Svetlana Kalinina, PhD, Institute of \\ Biology, Karelian Research Centre, Russian Academy of Sciences, 11, \\ J Morphol Sci 2019;36:247-254. \\ Pushkinskaya st., Petrozavodsk 185910, Russia \\ (e-mail: cvetnick@yandex.ru).
}

\begin{abstract}
Keywords

- canidae

- compared anatomy

- corpora arenacea

- microscopic animal anatomy

- pineal gland

Introduction The aim of the present study was to determine the morphological features of the pineal gland in three closely related Canidae species (raccoon dog, Nyctereutes procyonoides Gray, 1834; silver fox, Vulpes vulpes L., 1758; and blue fox, Vulpes lagopus L., 1758) of different ages during the breeding (spring) and nonbreeding (winter) periods.

Materials and Methods Histological analysis of the pineal glands of canids was performed.

Results The morphological changes in the pineal gland detected in the current study are either age-associated, including increase in the reticular fibers and vascularization in the studied species, as well as increase in the amount of the protruding septae in the blue fox, or seasonally related, including an increase in the number and size of blood vessels. The present work reported two types of pigments: lipofuscin (primarily in the silver fox) and melanin (primarily in the raccoon dog and in the blue fox). The pineal gland in the blue fox is characterized by the ability to form corpora arenacea.

Conclusions The present study provides the first insight into the morphological changes of the pineal gland in three closely related Canidae species of different ages during the breeding (spring) and nonbreeding (winter) periods, and showed some species-specific features of gland morphology. The aspects concerning the biogenesis of the calcium concretions and the factors influencing the accumulation of pigments need further investigation.
\end{abstract}

\section{Introduction}

The structure and ultrastructure of the mammalian pineal gland have been largely described in previous reviews. ${ }^{1,2}$ As a major component of the photoneuroendocrine system, the pineal gland appears to be a "neuroendocrine transducer", receiving external stimuli (photoperiodic information) from the retina and the circadian suprachiasmatic nuclei ( $\mathrm{SCN}$ ) oscillator and converting this in hormonal responses (especially melatonin [MEL] production). ${ }^{3,4}$ Therefore, the pineal gland allows mammals to respond to the daily or annual changes in the photoperiod by adaptive alterations of their physiological state. The best example of such photoperiod- dependent physiological functions in the year is the activation/inactivation of the reproductive axis, a phenomenon in which the pineal and its MEL rhythm are essential in most temperate latitude mammals, ${ }^{3}$ including Canids.

The closely related Canids, blue fox (Vulpes lagopus), silver fox (Vulpes vulpes), and the raccoon dog (Nyctereutes procyonoides), are fur-bearing animals, whose physiological traits (reproduction, moulting, etc.) are specifically and reversibly regulated on a seasonal basis. ${ }^{5-8}$ The question arises whether the morphology of the pineal gland in canids have been changing during the breeding and nonbreeding periods, as well as with advancing age. The literature contains some descriptions of pineal morphology, including age-related received

September 4, 2018

accepted

July 20, 2019
DOI https://doi.org/

10.1055/s-0039-1698373. ISSN 2177-0298.
Copyright $\odot 2019$ by Thieme Revinter

Publicações Ltda, Rio de Janeiro, Brazil
License terms

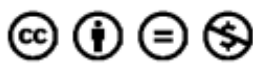


changes, only in a few canids (blue fox ${ }^{9}$; $\operatorname{dog}^{10,11}$; fox ${ }^{12}$; and silver fox ${ }^{13}$ ). No analyses have been performed of the influence of season and age on morphology of the the pineal gland in canids.

Therefore, the aim of the present study was to determine the morphological features of the pineal gland in three closely related Canidae species (raccoon dog, silver, and blue foxes) of different ages during the breeding (March) and nonbreeding (December) periods.

\section{Materials and Methods}

The research was carried out using the equipment of the Core Facility of the Karelian Research Centre of the Russian Academy of Sciences. All of the experiments were conducted according to the EU Directive 2010/63/EU for animal experiments with the special permission of the Local Ethic Committee of the Institute of Biology.

\section{Animals and Material Collection}

The three Canidae species (raccoon dog, N. procyonoides Gray, 1834; silver fox, V. vulpes L., 1758; blue fox, V. lagopus L., 1758) were used ( - Table 1 ). The animals were reared in a fur farm, “Russian sable", (Moscow region, Russia, $56^{\circ} 02^{\prime} \mathrm{N}$, $37^{\circ} 58^{\prime} \mathrm{E}$ ) in individual, outdoor cages. They were fed in accordance with the nutritional regime for fur-bearing animals with free access to water. The animals were sacrificed between $8 \mathrm{Am}$ and 9 Am in March (breeding period; photoperiod of 12-hour light/12-hour dark) and in December (period of sexual rest; photoperiod of 07-hour light/17-hour dark), in line with the approved procedure for fur animal farms. The pineal glands were removed immediately after skinning.

\section{Histology and Microscopic Examination}

After being removed, the pineal glands were immediately fixed by immersion in $10 \%$ neutral buffered formalin at room temperature for histological preparations. The fixed glands were dehydrated in ascending series of alcohol grades, cleared in xylene, then embedded in paraffin wax and sectioned with a thickness of $5 \mu \mathrm{m}$ in the dorsoventral or sagittal planes. The sections were then stained with Ehrlich hematoxylin and counterstained with eosin (H\&E), and with Masson-Goldner for the visualization of connective tissue and silver impregnation for reticular fibers. The stained sections were then mounted in distyrene plasticizer and observed under an
AxioScope.A1 light microscope (Carl Zeiss, Oberkochen, Germany). The images were made using an AxioCam MRc 5 video camera (Carl Zeiss, Oberkochen, Germany), connected to the microscope, and the image-processing system AxioVision (Carl Zeiss, Oberkochen, Germany).

\section{Results and Discussion}

\section{Gross Morphology of the Pineal Gland in Canids - General Comments}

The pineal gland develops as an evagination of the diencephalic roof. In most mammals, it forms a solid mass, extending from the region located between the habenular and posterior commissures in the caudodorsal direction. The mammalian pineal gland joins with the pineal recess of the third ventricle. ${ }^{2}$

The pineal gland of the studied species is classified as $A$ or $\mathrm{AB}$ type according to the Vollrath classification ${ }^{2}$ and displays large individual variability in shape and size (-Fig. 1). Generally, the pineal gland is a conical organ (up to 5$6 \mathrm{~mm}$ long and 3-4 mm wide) with or without invagination on the surface, and sometimes divided into 2 parts by connective tissue fibers. But, also as a result of the fact that the distal part of the gland does not increase in size during development, in the dorsoventral view, the pineal has the form of a ribbon lying in the immediate vicinity of the third ventricle. The raccoon dog often has a big conicalshaped gland with invagination on the surface; the organ of the silver fox is mostly also big and round or elongated; whereas in the blue fox two forms of pineal - ribbon-like and conical - are observed with the same frequency.

The pineal gland is surrounded by a pial capsule; the glandular parenchyma comprises the more numerous pinealocytes, cells with large nuclei of oval or round shape, less abundant glial cells, probably astrocytes, with highly heterochromatic (strongly stained) small nuclei, fibroblasts, blood vessels, reticular and collagen fibers.

\section{Species-specific Features of the Pineal Glands in Canids} Present findings inform about the late postnatal ontogenetic and seasonal changes in the morphology of the pineal gland in three Canidae species (raccoon dog, silver, and blue foxes). However, due to the fact that the studied mammals are monoestric, it is difficult to separate the effects of age and season on the morphology of the pineal gland.

Table 1 The experimental groups and specimen numbers

\begin{tabular}{|l|l|l|l|l|}
\hline \multirow{2}{*}{ Species } & \multicolumn{4}{|l|}{ Seasons and age periods } \\
\cline { 2 - 5 } & \multicolumn{2}{|l|}{ Winter } & \multicolumn{2}{l|}{ Spring } \\
\cline { 2 - 5 } & $\begin{array}{l}\text { Juvenile animals } \\
(6-8 \text { months old })\end{array}$ & $\begin{array}{l}\text { Adults in the period } \\
\text { of sexual rest } \\
(1.5-4.5 \text { years-old, } \\
\text { winter adults })\end{array}$ & $\begin{array}{l}\text { Animals in the first } \\
\text { fertile period } \\
(9-11 \text { months old) }\end{array}$ & $\begin{array}{l}\text { Adults in the } \\
\text { reproductive period } \\
\text { (2-5 years-old, } \\
\text { spring adults) }\end{array}$ \\
\hline Raccoon dog & $n=4$ & $n=4$ & $n=2$ & - \\
\hline Silver fox & $n=3$ & $n=4$ & $n=2$ & $n=2$ \\
\hline Blue fox & $n=4$ & $n=2$ & $n=2$ \\
\hline
\end{tabular}



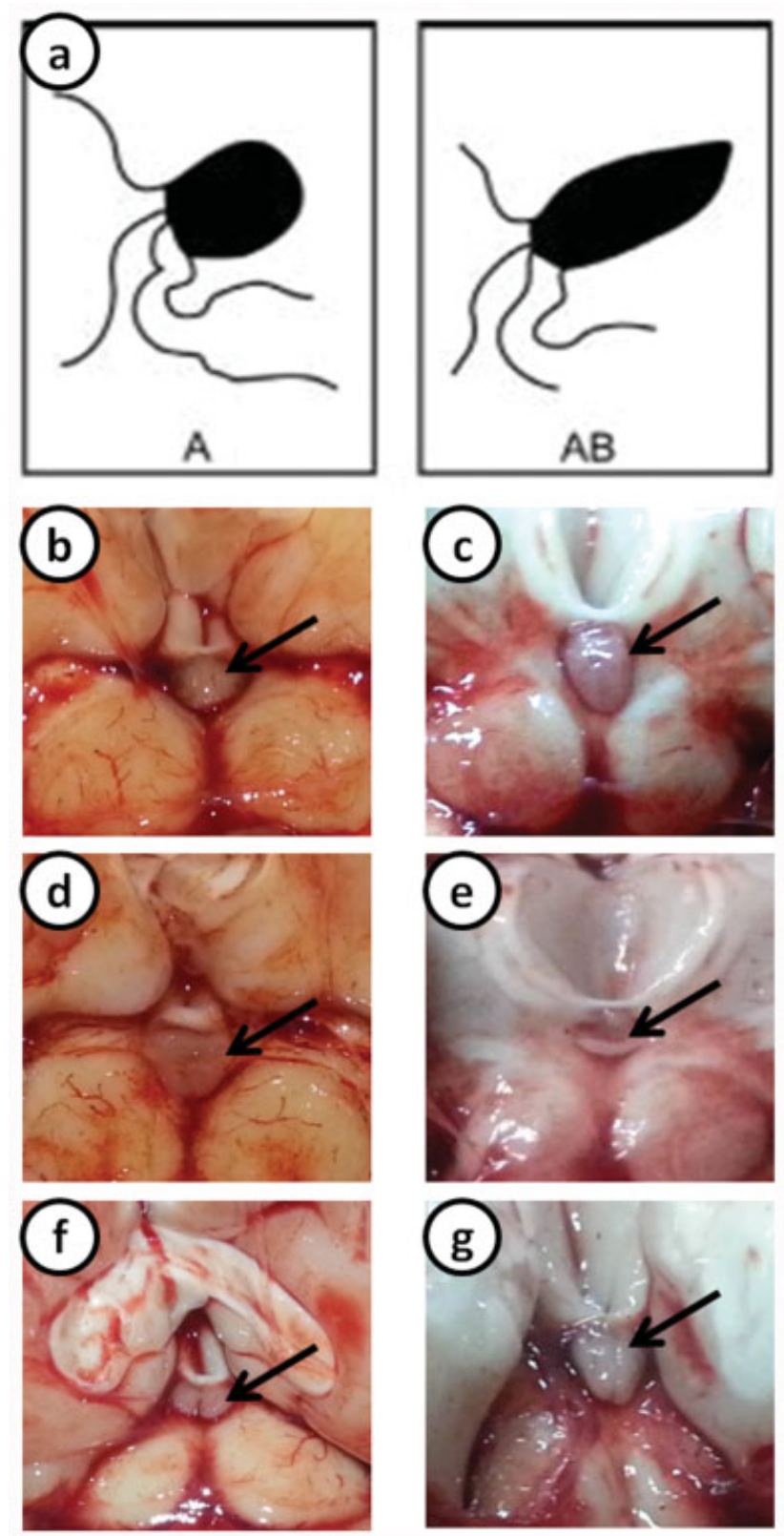

Fig. 1 Gross morphology of the pineal glands in Canids in situ. Caudal-dorsal view of the part of the brain after tilting of the cerebellum. The pineal gland (arrow) at the frontal edge of the colliculi is visible after slicing of the brain hemispheres. (a) Schematic representation of the $A$ and $A B$ forms of pineal glands according to the classification by Vollrath. ${ }^{2}(\mathrm{~b})-(\mathrm{g})$ In vivo photos, demonstrating the variability of shapes and sizes of the pineal glands: (b) oval-shaped (silver fox), (c) conical (blue fox), (d) conical with the invagination on the surface (raccoon dog), (e) ribbon-like (blue fox), (f), (g) pineal gland divided into two parts (silver and blue fox, respectively).

At the age of 6-8 months old, in the winter period, the pineal gland parenchyma in the studied Canids displays great cellularity: cells are randomly arranged, with no clear orientation (-Fig. 2). The differences in the densities of the cells and connective tissue fibers appear in the first fertile age (911 months old) in the spring by forming the functionally dissimilar parts: on the one side, the central and peripheral regions, and on the other side, the proximal and distal ones. In

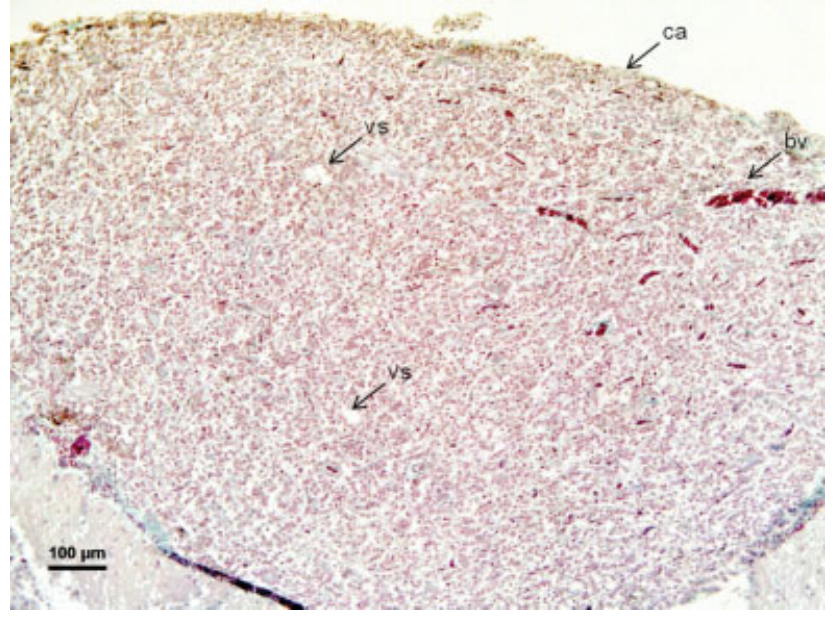

Fig. 2 Photomicrograph of a sagittal direction section of the pineal gland in a juvenile silver fox (winter). Capsule (ca), blood vessels (bv), vascular structures (vs). Masson-Goldner staining.

contrast to the peripheral area (cortex), the center (medulla) of the gland is characterized by a greater amount of cells and collagen, and by a lesser amount of reticular fibers. In the pineal of the blue fox, these differences are not so marked as in the other species studied. The distal regions of the pineal glands of the canids studied contain more reticular fibers, more pigments and more calcium concrements (if these structures appear). Our results are in accordance with previously published data that showed that the pineal cortex and medulla display differing cell densities (in sheep) $)^{14}$ and that the distal and proximal portions of the pineal gland differ in structure (size of pinealocytes, amount of astrocytes, nervous fibers, and fenestrae of capillary endothelium) (in cotton rats) $)^{15}$.

Light and electron microscopy has allowed the fine description of the ontogenesis of the mammalian pineal gland (in rats $^{16,17}$; dogs ${ }^{10,11}$; horses ${ }^{18}$; sheep ${ }^{14}$; and in humans ${ }^{19}$ ). But these data are contradictory. Several authors noted regressive signs in morphology, such as the increase in connective tissue fibers and calcium content (in rats ${ }^{16}$ ), but others (in humans ${ }^{19}$ ) revealed that the parenchymal cells of the gland do not undergo atrophy in adult life and there does not appear to be any pattern in the development of fibrosis or of gliosis in the pineal gland.

The amount of connective tissue fibers in the studied mammals (mostly collagen ones in raccoon dog and mostly reticular fibers in foxes) is increased with age, which is confirmed by the data obtained on rats ${ }^{16}$ and rabbits. ${ }^{20}$ In the winter and spring, the gland of adult blue foxes has a marked loose structure due to the great amount of reticular fibers. In the winter period, marked parenchymal cell clusters separated by connective tissue trabeculae extending from the capsule are observed.

Previously, it was defined that the minimum rate of rat pineal blood flow per gram exceeds that of most endocrine organs, equals that of the neurohypophysis, and is surpassed only by that of the kidney. ${ }^{21}$ Throughout life, the pineal gland in canids has a rich blood supply, but during the periods of reproductive activity (spring), the number or the size of blood 
vessels is increased compared with the period of sexual rest (winter). These findings confirm the well-known important role of the pineal and its hormone MEL in the photoperiodic control of reproductive functions in seasonally-breeding mammals. ${ }^{4}$ However, according to other researchers, in blue foxes, changes in the MEL level during the year were not observed; ${ }^{22}$ in the raccoon dog, the blood plasma concentration of MEL in December was higher than in March;23 and in the silver fox, contrarily, its level was higher in March than in December. $^{24}$

In a 1.5-year-old raccoon dog, the pinealocytes in the central region of the gland form glandular structures with a central lumen, bordered with epithelial cells (-Fig. 3). Similar findings were also revealed in bovine embryos, ${ }^{25}$ in which the appearance of these structures could be related with the act of MEL secretion. Other vascular structures are visible in the parenchyma at all of the studied ages (-Fig. 2 ).

Rare mitoses are observed in animals in the $1^{\text {st }}$ year of life, and are found in adults in the winter and spring. Degenerated cells, both pinealocytes and fibroblasts (with pyknotic, karyolitic and karyorrhexic structures), are frequently observed in the pineals of the raccoon dog and of the blue fox at the $1^{\text {st }}$ year of life, but their occurrence is decreased with age (-Fig. 4).

Similarly to other authors, ${ }^{16,26-29}$ we have also detected marked differences in the staining intensity and in the chromatin state in the nuclei of pinealocytes. Conditionally, we divided the nuclei in three types: dark (with more uniformly distributed and dense chromatin, and a hardly discernible nucleolus), light (light staining nuclei with $\geq 1$ visible nucleoli), and intermediate (has intermediate staining features and finely dispersed chromatin without prominent nucleoli) (-Fig. 5). Previous findings based on electron microscopic, ${ }^{29}$ electrophysiological $^{30}$ and immunohistochemical ${ }^{31}$ investigations of the pineal gland provide reason to suspect that the population of pinealocytes is highly heterogenic, and that MEL synthesis varies significantly among individual cells. The light and intermediate types of nuclei are more numerous than dark ones at the all studied ages in any season.

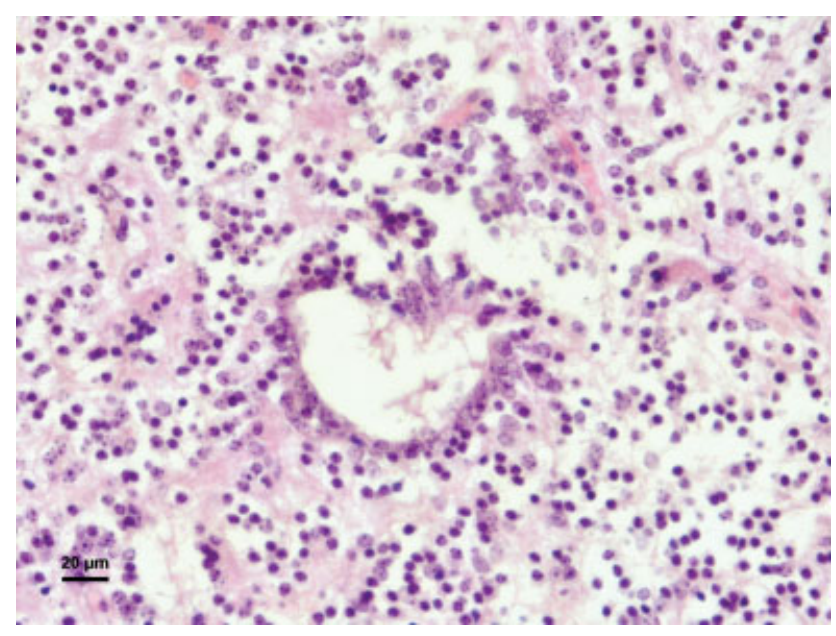

Fig. 3 Photomicrograph of a section of the pineal gland in adult raccoon dog ( 1.5 years old, winter), the proximal part of the gland. Round glandular structures with a central lumen, bordered with epithelial cells. H\&E.

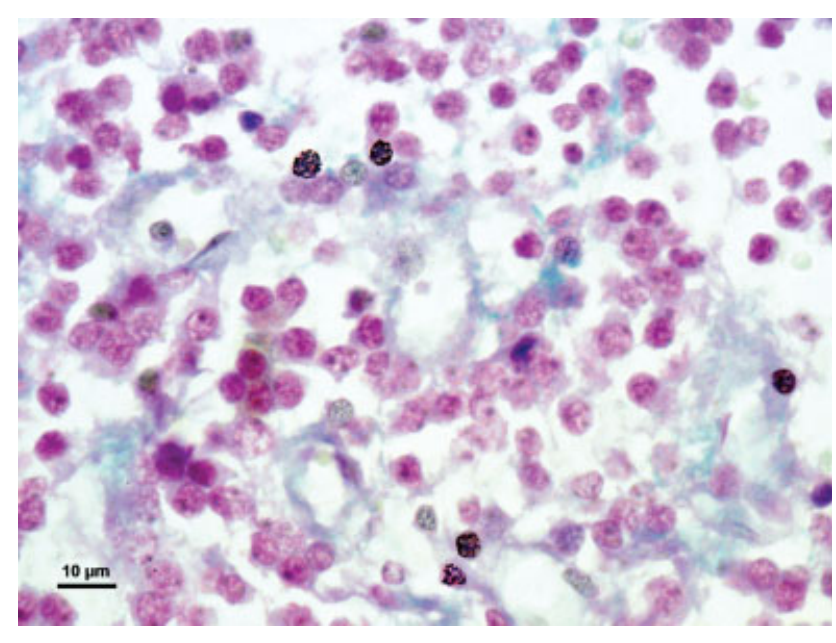

Fig. 4 Photomicrograph of a section of the pineal gland in a juvenile blue fox (winter), central area. Nuclei (purple), connective tissue fibers (blue); pyknotic nuclei (black). Masson-Goldner staining.

In several Canids (raccoon $\operatorname{dog}^{23}$; silver fox ${ }^{24} ; \operatorname{dog}^{32}$ ) and other seasonally breeding animals (European hamster ${ }^{33}$ ) a marked seasonal variation in MEL synthesis was detected, whereas it was not observed in the blue fox. ${ }^{22}$

The present work reported two types of cytoplasmic pigments, which according to the morphology and staining features, most probably correspond to lipofuscin (yellowishbrown) and melanin (strong argirophyl reaction, as shown by silver impregnation). The pineal gland of the silver fox contains a small amount of yellowish-brown pigments during the $1^{\text {st }}$ year of life; it increases in the adults, especially in the winter period, and is found mostly in the periphery of the proximal part of the gland (-Fig. 6). In contrast with the silver fox, the other studied species have very small amount of yellowishbrown pigments in their pineal glands throughout life (-Fig.5).

Highly pigmented black-colored glands were observed among the raccoon dog (-Fig. 7) and the blue fox at the ages between 6 and 8 months old. In these cases, the pigment was melanin. Our finding is in line with the data of Capucchio

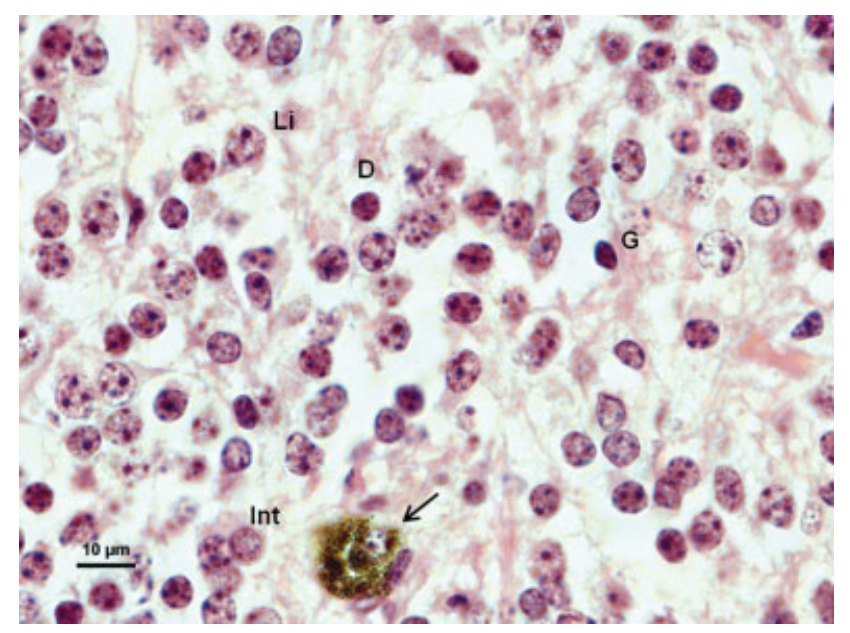

Fig. 5 Photomicrograph of a section of the pineal gland in a juvenile raccoon dog, central area. Pigment granules (arrow), nuclei of glial cells (G), "light” (Li), “intermediate" (Int) and "dark" (D) types of nuclei of pinealocytes. H\&E. 


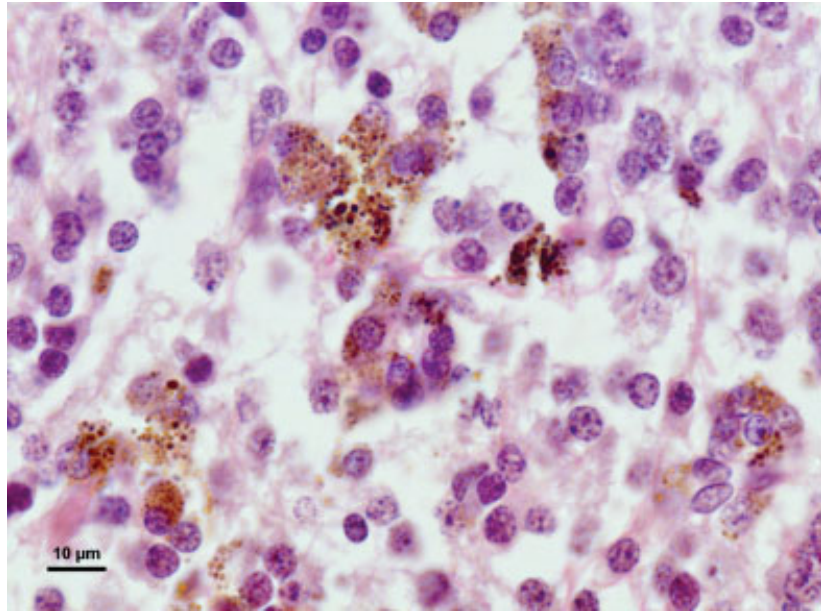

Fig. 6 Photomicrograph of a section of the pineal gland in an adult silver fox (winter), proximal part of the gland. Large accumulation of pigment granules. H\&E.

et $\mathrm{al}^{18}$ who considered that the presence of melanosis is unrelated to the age of horses. Also, Quay ${ }^{34}$ has not found any relationship between the amount of pineal pigment with age, gender, or the reproductive state in rodents. In the pineal glands of dogs and cats, the pigment is normally found. ${ }^{35,36}$ However, several authors revealed that the increase in the amount of melanin in the pineal gland could be defined with increasing age (in humans ${ }^{19}$ ) or after exposure to constant darkness (in bats ${ }^{37}$ ).

Considering the fact that the mammalian pinealocytes are phylogenetically derived from the true photoreceptors, the pineal melanin could represent a phylogenetic relic whose developmental history can be traced to the pigmented epithelium of the retina. ${ }^{37}$ Pigmented cells may constitute a special type of pinealocyte according to their ultrastructural features and the presence of pigment granules. ${ }^{35}$ Alternatively, pineal melanin may be another structure in the mammalian pineal gland which has no apparent function. Pineal components that have no recognized function include synaptic ribbons, cilia and ciliary precursor materials, intrapineal neurons, pinealocyte intermediate filaments, and acervuli (calcium concrements, brain sand, corpora arenacea). ${ }^{37}$

The last structures are the most intriguing elements in the pineal gland. Besides that, the corpora arenacea could also occur in the leptomeninges, in the habenular commissure, and in the choroid plexus. ${ }^{38}$ The pineal gland is able to form the deposits due to the high calcium content and the high phosphate turnover compared with other tissues. ${ }^{38,39}$ The pineal brain sand has long been studied because of its association with aging, $^{38,40,41}$ MEL production, ${ }^{42}$ or neurological disorders, ${ }^{43}$ but the biological significance of pineal calcium concrements, however, is still unknown. The relevance of acervuli to aging is still arguable; in general views, their incidence and amount are believed to increase with age $e^{44,45}$ despite several irrelevant cases. ${ }^{19,46}$ It is also assumed that formation of concrements could increase during the reproductive period in connection with the functional load on the pineal gland; ${ }^{41}$ therefore, the acervuli could possess a dynamic nature. ${ }^{47}$

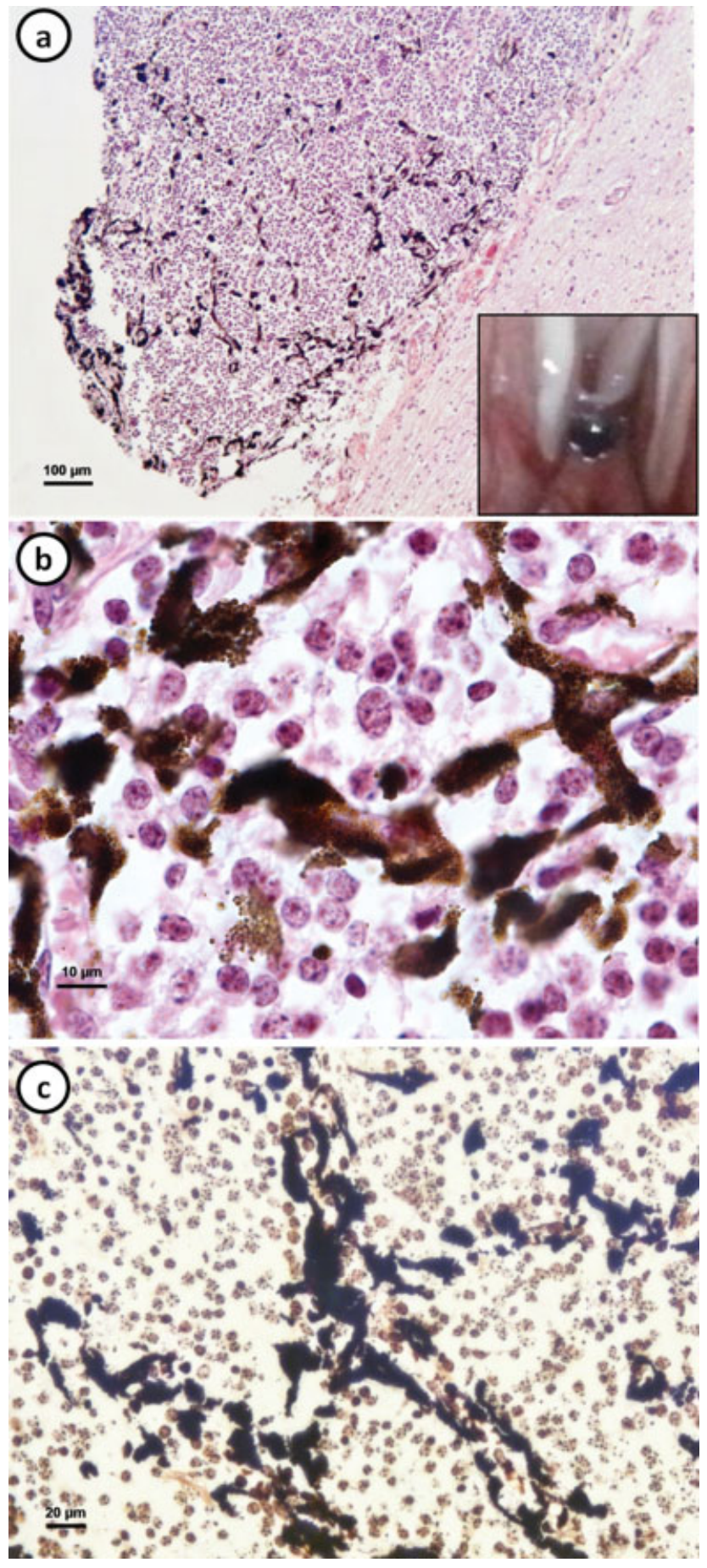

Fig. 7 Photomicrograph of the highly pigmented black-colored pineal gland in a juvenile raccoon dog (6-8 months old, winter). (a) Distal part of the gland. In the bottom right - macroscopic view of the gland. (b), (c) The magnified sectors of the distal part of the gland with abundant melanin aggregations. (a), (b) H\&E, (c) Silver impregnation.

Brain sand is often found in the pineal gland of humans 48 and of many mammals (rodents ${ }^{28,49}$; carnivorous $^{9,38}$ ). However, in our study, it was revealed that in contrast with the pineal glands of the silver fox and of the raccoon dog, the pineal gland of the blue fox appears to have the greatest ability to form calcium concretions, visible at light microscopic level, at all of the studied ages. In 1 of 4 studied 
raccoon dogs aged 1.5 years old, we observed only 1 acervulus $\sim 15 \mu \mathrm{m}$ in diameter located in the pineal capsule, whereas in the gland of the silver fox we detected the possible site of the calcification. In the pineal gland of the blue fox, the calcified concrements were found in the parenchyma of the distal part of the gland, in the capsule surrounding it, and in the protruding septae (-Fig. 8).

At the light microscopic level, they are observed at the all studied ages (in 1 of 3 animals aged between 6 and 8 months old, in 2 of 2 aged between 9 and 11 months old, in 1 of 2 winter adults and in 1 of 2 spring adults), but in not all individuals. The size of the deposits is up to $40 \mu \mathrm{m}$. Some glands showed accumulation of numerous deposits of different sizes, whereas the others revealed only few acervuli.

Other authors revealed the differences in the structure of capsular concrements and of parenchymal ones. ${ }^{38}$ The first show a clear concentric lamination, but the second have a globular structure. As the capsule and septae of the pineal are formed by the arachnoid and pia mater sheats of the meninges, the concrements of the capsule and septae are an example of meningeal calcification. ${ }^{38}$ Similarly, in our study, the acervuli from the capsule had a laminated structure, but most of the concrements formed in the pineal parenchyma also had the alternative layers of light- and dark-stained rings (-Fig. 8). Others were strong dark-stained and third were light-stained and seemed to be the hollow structure (in sections stained with H\&E) ( - Fig. 8 c, e). However, in samples stained according to the Masson-Goldner method, the acervuli colored pink, light green, or both, and some of them had black rings, which indicated the different composition of the concrements ( - Fig. $8 \mathbf{b}, \mathbf{d}$ ). In the immediate vicinity of the acervuli, the denegerated cells, fibroblasts, and collagen fibers are often observed.

To date, there is no clear understanding of how and why calcium concretions form, but some mechanisms for their formation are suggested. Among them the impairment of calcium ion-dependent ATPase, changes in calcium channels or a constant depolarization of pinealocytes calcium pump leading to elimination of calcium out of the cell ${ }^{50}$; the death or degeneration of the pinealocytes, resulting in an overall

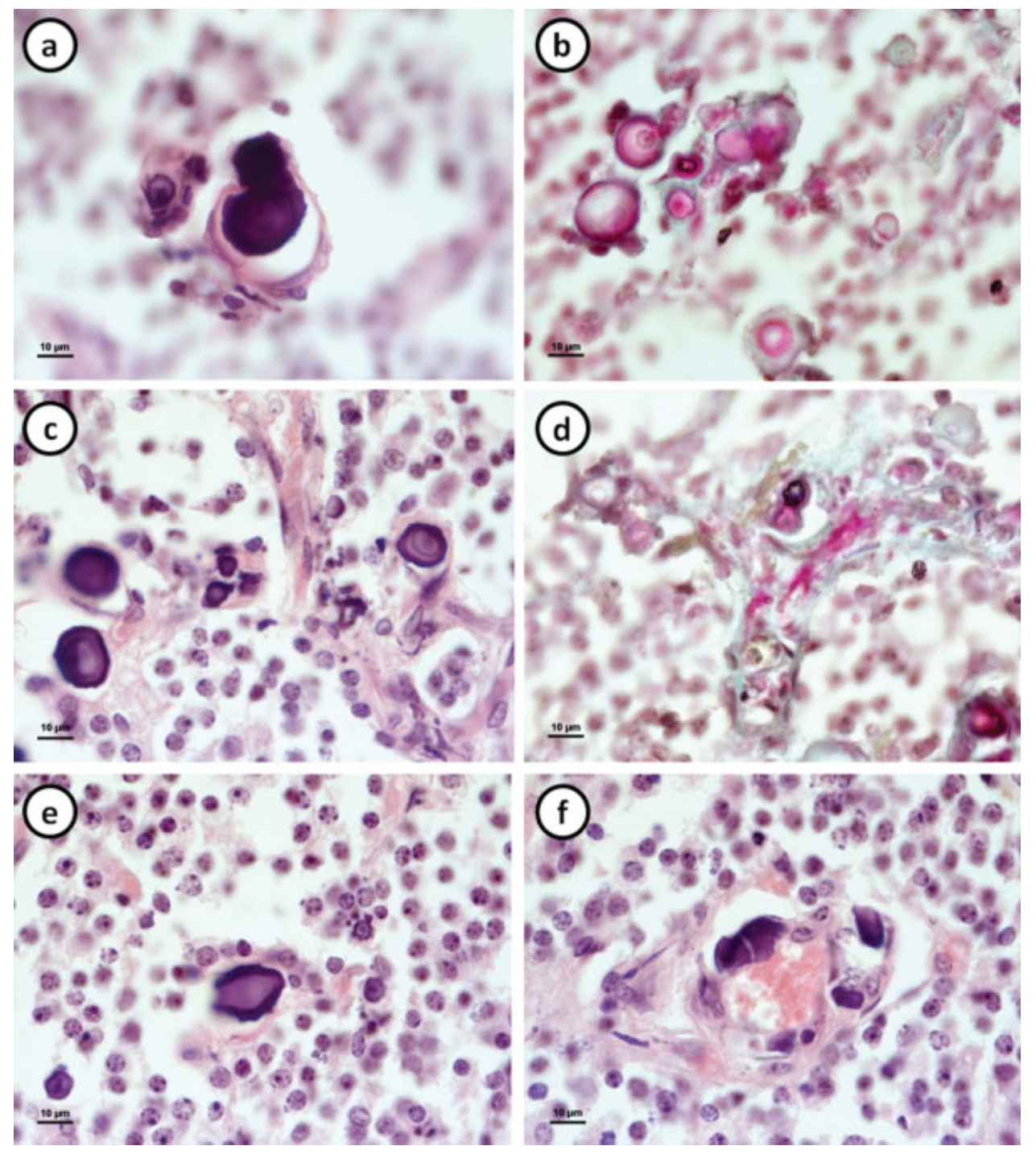

Fig. 8 Various locations and shapes of corpora arenacea in the pineal gland of adult blue fox (1.5-4.5 years old, winter). Acervuli are in parenchyma: (a) Hematoxylin and eosin. (b) Masson-Goldner staining. Acervuli are in trabeculae: (c) H\&E. (d) Masson-Goldner staining. (e) Acervulus has a hollow structure. H\&E. (f) Calcification of blood vessel. H\&E. 
decrease in the pineal gland activity ${ }^{28,51}$ and the active participation of the tryptase mast cells in the pineal calcification process as sites where it starts. ${ }^{46}$

Reviewing the data available about pineal calcification, one can conclude that a multifactorial mechanism may be responsible for its formation. ${ }^{38}$ Moreover, the nature and crystallinity of the inorganic tissue of the pineal concretions provide reason to assume that the corpora arenacea is of a physiological rather than pathological ossification type with characteristics between enamel and dentine, but with more marked analogies toward the latter. ${ }^{48}$

\section{Conclusions}

The present study provides the first insight into the morphological features of the pineal gland in three closely related Canidae species (raccoon dog, silver, and blue foxes) of different ages during the breeding (spring) and nonbreeding (winter) periods. The morphological changes in the pineal gland detected in the current study are either ageassociated, including an increase in the reticular fibers and vascularization in the studied species, as well as an increase in the amount of the protruding septae in the blue fox, or seasonally related, including an increase in the number and size of blood vessels. The present work reported two types of pigments: lipofuscin (primarily in the silver fox) and melanin (primarily in the raccoon dog and in the blue fox). The pineal gland in the blue fox is characterized by the ability to form corpora arenacea. The aspects concerning the biogenesis of the calcium concretions and the factors influencing the accumulation of pigments need further investigation.

\section{Funding Details}

The study was performed under state order (project $\mathrm{N}^{\circ}$ 0218-2019-0073).

\section{Conflicts of Interests}

The authors have no conflicts of interests to declare.

\section{Acknowledgments}

The authors are grateful for the help in conducting the research to the director of the fur farm "Russian Sable," Ph.D. Shevyrkov V. L., to the head of the laboratory of ecological biochemistry of Institute of Biology of the Karelian Research Centre of the Russian Academy of Sciences, Ph.D. Murzina S. A., and to the researchers of the laboratory of animal ecological physiology of Institute of Biology of the Karelian Research Centre of the Russian Academy of Sciences Evgeniy Khizhkin and Artem Morozov for the assistance in the present study.

\section{References}

1 Pévet P. Anatomy of the pineal gland of mammals. In: Relkin R., eds. Current Endocrinology: The Pineal Gland. Elsevier BiomedicalAmsterdam1983:1-75

2 Vollrath L. The pineal organ. In: Oksche A, Vollrath L, eds. Handbuch Der Mikroskopischen Anatomie Des Menschen, vol 7. SpringerBerlin, Heidelberg, New York1981
3 Goldman BD. Mammalian photoperiodic system: formal properties and neuroendocrine mechanisms of photoperiodic time measurement. J Biol Rhythms 2001;16(04):283-301

4 Simonneaux V, Ribelayga C. Generation of the melatonin endocrine message in mammals: a review of the complex regulation of melatonin synthesis by norepinephrine, peptides, and other pineal transmitters. Pharmacol Rev 2003;55(02):325-395

5 Asikainen J. Wintering strategy of the boreal raccoon dog (Nyctereutes procyonoides) - Applications to farming practice. Publications of the University of Eastern Finland. Dissertations in Forestry and Natural Sciences No 111. Joensuu2013

6 Fuglei E. Physiological adaptations of the Arctic fox to high Arctic conditions [Ph.D. dissertation], University of Oslo, Oslo, Norway; 2000

7 Korhonen H, Harri M. Seasonal changes in thermoregulation of the raccoon dog (Nyctereutes procyonoides Gray 1834). Comp Biochem Physiol A Comp Physiol 1984;77(02):213-219

8 Sillero-Zubiri C, Hoffmann M, Macdonald DW. Canids: Foxes, Wolves, Jackals and Dogs. IUCN/SSC Canid Specialist Group, Published by: IUCNGland, Switzerland and Cambridge, UK2004

9 Bulc M, Lewczuk B, Prusik M, Gugołek A, Przybylska-Gornowicz B. Calcium concrements in the pineal gland of the Arctic fox (Vulpes lagopus) and their relationship to pinealocytes, glial cells and type I and III collagen fibers. Pol J Vet Sci 2010;13(02):269-278

10 Calvo J, Boya J, García-Mauriño JE, Lopez-Carbonell A. Postnatal development of the dog pineal gland: electron microscopy. J Pineal Res 1990;8(03):245-254

11 Calvo J, Boya J, García-Mauriño A, López Carbonell A. Postnatal development of the dog pineal gland. Light microscopy. Histol Histopathol 1990;5(01):31-36

12 Karasek M, Hansen JT. Ultrastructure of the pineal gland of the fox. Am J Anat 1982;163(03):257-267

13 Kolesnikova LA. [The epiphysis of relatively wild and domesticated foxes: the morphofunctional changes over the course of 24 hours]. Fiziol Zh Im I M Sechenova 1996;82(02):91-97

14 Redondo E, Regodon S, Masot J, Gázquez A, Franco A. Postnatal development of female sheep pineal gland under natural inhibitory photoperiods: an immunocytochemical and physiological (melatonin concentration) study. Histol Histopathol 2003;18(01): 7-17

15 Sakai Y, Hira Y, Matsushima S. Regional differences in the pineal gland of the cotton rat, Sigmodon hispidus: light microscopic, electron microscopic, and immunohistochemical observations. J Pineal Res 1996;20(03):125-137

16 Calvo J, Boya J. Postnatal evolution of the rat pineal gland: light microscopy. J Anat 1984;138(Pt 1):45-53

17 Ferreira-Medeiros M, Mandarim-de-Lacerda CA, Correa-Gillieron EM. Pineal gland post-natal growth in rat revisited. Anat Histol Embryol 2007;36(04):284-289

18 Capucchio MT, Márquez M, Pregel P, et al. Parenchymal and vascular lesions in ageing equine brains: histological and immunohistochemical studies. JComp Pathol 2010;142(01):61-73

19 Tapp E, Huxley M. The histological appearance of the human pineal gland from puberty to old age. JPathol 1972;108(02): 137-144

20 López-Muñoz F, Boya J, Calvo JL, Marín F. Immunohistochemical localization of glial fibrillary acidic protein (GFAP) in rat pineal stalk astrocytes. Histol Histopathol 1992;7(04):643-646

21 Goldman H, Wurtman RJ. Flow of blood to the pineal body of the rat. Nature 1964;203(4940):87-88

22 Smith AJ, Mondain-Monval M, Andersen Berg K, et al. Effects of melatonin implantation on spermatogenesis, the moulting cycle and plasma concentrations of melatonin, LH, prolactin and testosterone in the male blue fox (Alopex lagopus). JReprod Fertil 1987;79(02):379-390

23 Asikainen J, Mustonen A-M, Hyvärinen H, Nieminen P. Seasonal reproductive endocrine profile of the raccoon dog (Nyctereutes procyonoides)-effects of melatonin and food deprivation. JExp Zoolog A Comp Exp Biol 2003;299(02):180-187 
24 Forsberg M, Madej A. Effects of melatonin implants on plasma concentrations of testosterone, thyroxine and prolactin in the male silver fox (Vulpes vulpes). J Reprod Fertil 1990;89(01):351-358

25 Regodón S, Pozo D, Roncero V. Histomorphogenesis and immunohistochemical study of the bovine pineal gland (Bos taurus) during prenatal development (160 days of gestation to birth). Histol Histopathol 2006;21(10):1043-1053

26 Al-Hussain SM. The pinealocytes of the human pineal gland: A light and electron microscopic study. Folia Morphol (Warsz) 2006;65(03):181-187

27 Hira Y, Sakai Y, Matsushima S. Comparisons of sizes of pinealocyte nuclei and pinealocytes in young and adult Chinese hamsters (Cricetulus griseus) under different photoperiod conditions.J Pineal Res 1989;7(04):411-418

28 Humbert W, Pévet P. The pineal gland of the aging rat: calcium localization and variation in the number of pinealocytes. JPineal Res 1995;18(01):32-40

29 Pévet P. On the presence of different populations of pinealocytes in the mammalian pineal gland. J Neural Transm (Vienna) 1977; 40(04):289-304

30 Sibarov DA, Kovalenko RI, Nozdrachev AD. [Pinealocyte functioning in stress during daytime in rats]. Ross Fiziol Zh Im I M Sechenova 2000;86(08):1049-1056

31 Rath MF, Coon SL, Amaral FG, Weller JL, Møller M, Klein DC. Melatonin synthesis: Acetylserotonin O-methyltransferase (ASMT) is strongly expressed in a subpopulation of pinealocytes in the male rat pineal gland. Endocrinology 2016;157(05):2028-2040

32 Zań RS, Roliński Z, Kowalski CJ, Bojarska-Junak A, Madany J. Diurnal and seasonal changes in endogenous melatonin levels in the blood plasma in dogs. Pol J Vet Sci 2013;16(04):759-761

33 Garidou ML, Vivien-Roels B, Pévet P, Miguez J, Simonneaux V. Mechanisms regulating the marked seasonal variation in melatonin synthesis in the European hamster pineal gland. Am J Physiol Regul Integr Comp Physiol 2003;284(04):R1043-R1052

34 Quay WB. Pineal chemistry in cellular and physiological mechanisms. Ill.: Thomas; 1974

35 Calvo J, Boya J, Garcia-Mauriño JE, Lopez-Carbonell A. Structure and ultrastructure of the pigmented cells in the adult dog pineal gland. JAnat 1988;160:67-73

36 Calvo JL, Boya J, García-Mauriño JE, Rancaño D. Presence of melanin in the cat pineal gland. Acta Anat (Basel) 1992;145 (01):73-78

37 Bhatnagar KP, Hilton FK. Observations on the pineal gland of the big brown bat, Eptesicus fucus: possible correlation of melanin intensification with constant darkness. Anat Rec 1994;240(03): 367-376

38 Vígh B, Szél A, Debreceni K, Fejér Z, Manzano e Silva MJ, VíghTeichmann I. Comparative histology of pineal calcification. Histol Histopathol 1998;13(03):851-870

39 Borell U, Orström A. The turnover of phosphate in the pineal body compared with that in other parts of the brain. Biochem J 1947;41 (03):398-403

40 Doyle AJ, Anderson GD. Physiologic calcification of the pineal gland in children on computed tomography: prevalence, observer reliability and association with choroid plexus calcification. Acad Radiol 2006;13(07):822-826

41 Zimmerman RA, Bilaniuk LT. Age-related incidence of pineal calcification detected by computed tomography. Radiology 1982;142(03):659-662

42 Kunz D, Schmitz S, Mahlberg R, et al. A new concept for melatonin deficit: on pineal calcification and melatonin excretion. Neuropsychopharmacology 1999;21(06):765-772

43 Sandyk R. Pineal and habenula calcification in schizophrenia. Int J Neurosci 1992;67(1-4):19-30

44 Admassie D, Mekonnen A. Incidence of normal pineal and chroids plexus calcification on brain CT (computerized tomography) at Tikur Anbessa Teaching Hospital Addis Ababa, Ethiopia. Ethiop Med J 2009;47(01):55-60

45 Mori R, Kodaka T, Sano T. Preliminary report on the correlations among pineal concretions, prostatic calculi and age in human adult males. Anat Sci Int 2003;78(03):181-184

46 Maślińska D, Laure-Kamionowska M, Deręgowski K, Maśliński S. Association of mast cells with calcification in the human pineal gland. Folia Neuropathol 2010;48(04):276-282

47 Champney TH, Joshi BN, Vaughan MK, Reiter RJ. Superior cervical ganglionectomy results in the loss of pineal concretions in the adult male gerbil (Meriones unguiculatus). Anat Rec 1985;211 (04):465-468

48 Bocchi G, Valdre G. Physical, chemical, and mineralogical characterization of carbonate-hydroxyapatite concretions of the human pineal gland. J Inorg Biochem 1993;49(03):209-220

49 Diehl BJM. Time-related changes in size of nuclei of pinealocytes in rats. Cell Tissue Res 1981;218(02):427-438

50 Krstić R. Pineal calcification: its mechanism and significance. J Neural Transm Suppl 1986;21:415-432

51 Schmid HA. Decreased melatonin biosynthesis, calcium flux, pineal gland calcification and aging: a hypothetical framework. Gerontology 1993;39(04):189-199 